DOI: 10.1002/adsc.201000772

\title{
Rhodium-Catalysed Alkoxycarbonylative Cyclisation Reactions of 1,6-Enynes
}

\author{
Firat Ziyanak, ${ }^{a}$ Melih Kus, ${ }^{a}$ and Levent Artok $^{a, *}$ \\ a Department of Chemistry, Faculty of Science, Izmir Institute of Technology, Urla 35430, Izmir, Turkey \\ Fax: (+90)-232-750-7509; phone: (+90)-232-750-7529; e-mail: leventartok@iyte.edu.tr
}

Received: October 13, 2010; Revised: January 11, 2011; Published online: April 12, 2011

Supporting information for this article is available on the WWW under http://dx.doi.org/10.1002/adsc.201000772.

\begin{abstract}
The rhodium-catalysed carbonylation of 1,6-enynes possessing an electron-deficient alkenyl moiety in an alcohol reagent in the presence of a rhodium complex proceeded stereo- and chemoselectively to afford exocyclic $\alpha, \beta$-enoates.
\end{abstract}

Keywords: alkoxycarbonylation; cyclisation; $\alpha, \beta$ enoates; 1,6-enynes; five-membered rings; rhodium

The hydroesterification of simple alkynes that forms $\alpha, \beta$-unsaturated esters is an extensively studied process, which is usually operated over a Pd-based catalyst in the presence of an alcohol reagent. ${ }^{[1]}$ There are also a few reported cases in which alkynes were carbonylated in alcohol reagents in the presence of rhodium complexes. However, the latter rhodium-catalysed method often resulted in double incorporation of the carbonyl moiety. ${ }^{[2]}$ For example, Mise reported that the Rh-catalysed carbonylation of internal alkynes in ethanol gave a 5-ethoxy-5 $H$-furan-2-one derivative as the main product. ${ }^{[3]}$ The carbonylation of phenyl-substituted acetylenes in the presence of alcohols was found to form 3-alkoxycarbonylindanones. ${ }^{[4]}$ Chatani reported that the rhodium-catalysed carbonylation of internal alkynes with pyridin-2-ylmethanol proceeded through a chelate-assisted transformation and a double hydroesterification, resulting in 1,4-dicarboxylate esters. ${ }^{[5]}$

The reactions that utilised nucleophiles other than alcohols, e.g., water, ${ }^{[6]}$ amines, ${ }^{[7]}$ or organoborons ${ }^{[8]}$ also resulted in double carbonylation of alkynes with rhodium catalysts, leading to cyclised products. The majority of these rhodium-catalysed carbonylation processes seem to involve the formation of carbonylated alkenylrhodium(I) species (I) that have a high propensity for insertion into $\mathrm{CO}$, giving rise to acylrhodium species (II) (Scheme 1). Protodemetalation

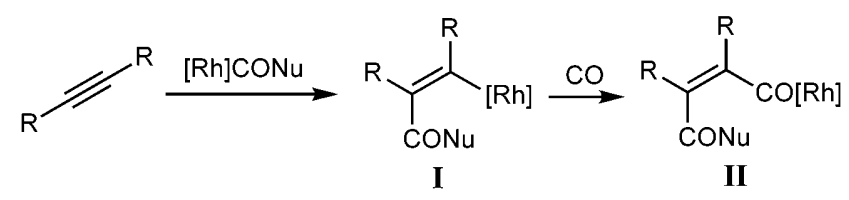

Scheme 1. Rhodium-promoted double carbonylation of alkyne.

of I has also been observed occasionally as a competing route..$^{[5,7,8 b, c]}$

Alkenylrhodium(I) species, such as I, that can be generated via the addition of several types of rhodium species, are also reactive leading to carborhodation of electrophilic sites, effecting $\mathrm{C}-\mathrm{C}$ bond formation. Such a formation has been described for a variety of cascade-type reactions that construct a functionalised cyclic product. ${ }^{[9]}$

Within this context, we have envisaged that alkynyl reagents bearing another unsaturated moiety in an appropriate position could also undergo alkoxycarbonylative cyclisation, thus being analogous to the reactions of in situ generated organorhodium ${ }^{[9]}$ and $\mathrm{Si}^{-}$ $\mathrm{Rh}^{[10]}$ species with the acceptors bearing two or more electrophilic sites.

To investigate this possibility, a 1,6-enyne (1a) having an ester functionality on the olefinic site was reacted in $\mathrm{MeOH}$ under $10 \mathrm{~atm}$ of $\mathrm{CO}$ at $100^{\circ} \mathrm{C}$ in the presence of $[\mathrm{RhCl}(\operatorname{cod})]_{2} \quad(5 \% \mathrm{Rh})$ for $16 \mathrm{~h}$ (Table 1, entry 1). This first attempt produced appreciably an ethylidenecyclopentane derivative bearing an ester group on one of the olefinic carbons (3aa) in $75 \%$ GC yield and the configuration of the olefinic group was assigned by an NOE study (Scheme 2).

It must be noted that 1,6-enynes usually undergo a Pauson-Khand-type reaction leading to cyclopentenones when subjected to rhodium-catalysed carbonylation reactions in an unreactive solvent, ${ }^{[11]}$ whereas no traces of cyclopentenone derivatives were detected within the product mixture in the present case. 

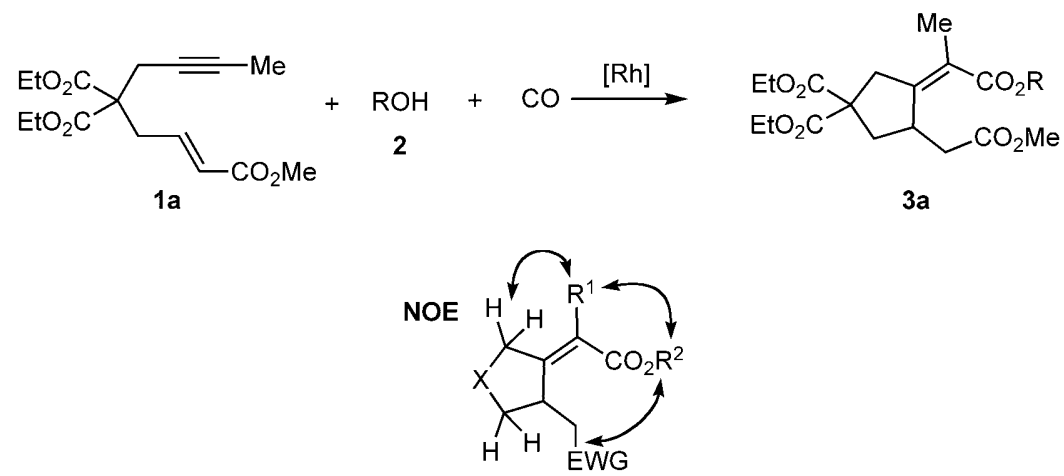

3

Scheme 2. Alkoxycarbonylative cyclisation of enyne 1a.

Table 1. Effect of reaction parameters on the rhodium-catalysed methoxycarbonylative cyclisation of $\mathbf{1 a}{ }^{[a]}$

\begin{tabular}{llllll}
\hline Entry & $\begin{array}{l}T \\
{\left[{ }^{\circ} \mathrm{C}\right]}\end{array}$ & $\begin{array}{l}P_{\mathrm{CO}} \\
{[\mathrm{atm}]}\end{array}$ & $\begin{array}{l}\text { Water } \\
{[\mathrm{mg}]}\end{array}$ & $\begin{array}{l}\text { Conv. } \\
{[\%]^{[\mathrm{b}]}}\end{array}$ & $\begin{array}{l}\text { Yield 3aa } \\
{[\%]^{[\mathrm{b}]}}\end{array}$ \\
\hline 1 & 100 & 10 & 0 & 100 & 75 \\
2 & 100 & 10 & 50 & 100 & 82 \\
3 & 100 & 10 & 250 & 100 & 53 \\
4 & 50 & 10 & 50 & 47 & 24 \\
5 & 80 & 10 & 50 & 88 & 67 \\
6 & 120 & 10 & 50 & 100 & 42 \\
7 & 100 & 5 & 50 & 100 & 68 \\
8 & 100 & 15 & 50 & 100 & 71 \\
\hline
\end{tabular}

[a] Reactions were run with $0.3 \mathrm{mmol}$ of $\mathbf{1 a}$ and the complex $[\mathrm{RhCl}(\mathrm{cod})]_{2}(5 \% \mathrm{Rh})$ in $5 \mathrm{~mL}$ of methanol for $16 \mathrm{~h}$.

[b] Determined by GC.

The presence of a small amount of water within the reaction mixture seems beneficial for the formation of 3aa. The presence of $50 \mathrm{mg}$ of water in the reaction medium caused an increase in the formation of 3aa (entry 2), but a larger content of water $(250 \mathrm{mg})$ was detrimental to the selectivity of the process (entry 3 ). Whereas increasing the reaction temperature to $120^{\circ} \mathrm{C}$ reduced the selective formation of the desired product, owing to the increased formation of intricate by-products, the conversion of the enyne 1a was not complete at the lower reaction temperatures of $50^{\circ} \mathrm{C}$ and $80^{\circ} \mathrm{C}$ (entries 4-6). The optimum $\mathrm{CO}$ pressure was set at $10 \mathrm{~atm}$; employing either lower or higher $\mathrm{CO}$ pressures than this lessened the opportunity for formation of the desired product (entries 7 and 8).

The activity of various rhodium complexes was also surveyed at the $5 \%$ of rhodium loading level (Table 2). The complexes, $\mathrm{Rh}(\operatorname{cod}){ }_{2} \mathrm{BF}_{4}$, $\left[\mathrm{RhCl}(\mathrm{CO})_{2}\right]_{2}, \quad[\mathrm{RhCl}(\mathrm{nbd})]_{2}$, and $[\mathrm{RhCl}(\mathrm{cod})]_{2}$ displayed similarly higher activities compared to the other complexes tested (entries 1-9), the yields being within the range of $77-82 \%$ with these complexes (entries 1-4). A somewhat lower but still reasonable
Table 2. Effect of the nature of the catalyst precursor on the rhodium-catalysed methoxycarbonylative cyclisation of $\mathbf{1 a} .^{[a]}$

\begin{tabular}{|c|c|c|c|}
\hline Entry & Catalyst & $\begin{array}{l}\text { Conv. } \\
{[\%]^{[\mathrm{b}]}}\end{array}$ & $\begin{array}{l}\text { Yield } \\
\text { 3aa }[\%]^{[b}\end{array}$ \\
\hline 1 & $\mathrm{Rh}(\operatorname{cod})_{2} \mathrm{BF}_{4}$ & 100 & 78 \\
\hline 2 & {$\left[\mathrm{RhCl}(\mathrm{CO})_{2}\right]_{2}$} & 100 & 79 \\
\hline 3 & {$[\mathrm{RhCl}(\mathrm{nbd})]_{2}$} & 100 & 77 \\
\hline 4 & {$[\mathrm{RhCl}(\operatorname{cod})]_{2}$} & 100 & 82 \\
\hline 5 & $\mathrm{RhCl}_{3} \cdot 3 \mathrm{H}_{2} \mathrm{O}$ & 100 & 68 \\
\hline 6 & {$\left[\mathrm{RhCl}\left(\mathrm{C}_{2} \mathrm{H}_{4}\right)_{2}\right]_{2}$} & 100 & 61 \\
\hline 7 & {$\left[\mathrm{Rhacac}\left(\mathrm{C}_{2} \mathrm{H}_{4}\right)_{2}\right]_{2}$} & 100 & 45 \\
\hline 8 & {$[\mathrm{RhOH}(\operatorname{cod})]_{2}$} & 100 & 52 \\
\hline 9 & {$\left[\mathrm{Rh}\left(\mathrm{PPh}_{3}\right)_{3}(\mathrm{CO}) \mathrm{H}\right]$} & 100 & 72 \\
\hline 10 & {$[\mathrm{RhCl}(\operatorname{cod})]_{2}+20 \% \mathrm{PPh}_{3}$} & 45 & 23 \\
\hline 11 & {$[\mathrm{RhCl}(\operatorname{cod})]_{2}+20 \% \mathrm{P}(\mathrm{OPh})_{3}$} & 71 & 50 \\
\hline 12 & {$[\mathrm{RhCl}(\operatorname{cod})]_{2}+10 \%$ dppe } & 14 & 10 \\
\hline 13 & {$[\mathrm{RhCl}(\mathrm{cod})]_{2}+10 \% \mathrm{dppp}$} & 65 & 31 \\
\hline 14 & {$[\mathrm{RhCl}(\operatorname{cod})]_{2}+5.5 \% R, S$-BINAP } & 48 & 25 \\
\hline $15^{[\mathrm{c}]}$ & {$[\mathrm{RhCl}(\operatorname{cod})]_{2}$} & 100 & 81 \\
\hline $16^{[\mathrm{d}]}$ & {$[\mathrm{RhCl}(\operatorname{cod})]_{2}$} & 100 & 70 \\
\hline
\end{tabular}

[a] Reactions were run with $0.3 \mathrm{mmol}$ of $\mathbf{1 a}, 50 \mathrm{mg}$ of water, and $5 \%$ of $\mathrm{Rh}$ at $100{ }^{\circ} \mathrm{C}$ under $10 \mathrm{~atm}$ of $\mathrm{CO}$ pressure in $5 \mathrm{~mL}$ of methanol for $16 \mathrm{~h}$.

[b] Determined by GC.

[c] Performed with $10 \%$ of $\mathrm{Rh}$.

[d] Performed with $3 \%$ of $\mathrm{Rh}$.

yield can be obtained even with the non-ligated $\mathrm{RhCl}_{3} \cdot 3 \mathrm{H}_{2} \mathrm{O}$ compound (entry 5).

In contrast with the activity of the phosphine-ligated rhodium complex, $\left[\mathrm{Rh}\left(\mathrm{PPh}_{3}\right)_{3}(\mathrm{CO}) \mathrm{H}\right]$, which led to relatively good result (entry 9), the presence of $\mathrm{PPh}_{3}, \mathrm{P}(\mathrm{OPh})_{3}$, or bidentate phosphorous ligands greatly reduced the activity of the rhodium catalyst coming from the $[\mathrm{RhCl}(\mathrm{cod})]_{2}$ complex (entries 1014). It was not necessary to use a higher concentration of rhodium, since a comparable result was also obtained at the $10 \% \mathrm{Rh}$ loading level (entry 15). Yet the yield decreased when using a lower levels of catalyst loading (3\% Rh) (entry 16). 
Table 3. Rhodium-catalysed alkoxycarbonylative reaction of 1a with various alcohols. ${ }^{[a]}$

\begin{tabular}{lll}
\hline Entry & $\mathrm{ROH}$ & Isolated Yield [\%] \\
\hline 1 & $\mathrm{MeOH}$ & $79(\mathbf{3 a a})$ \\
2 & $\mathrm{EtOH}$ & $66(\mathbf{3 a b})$ \\
3 & $\mathrm{PrOH}$ & $64(\mathbf{3 a c})$ \\
4 & $\mathrm{BuOH}$ & $64(\mathbf{3 a d})$ \\
5 & $i-\mathrm{PrOH}$ & $43(\mathbf{3 a e})$ \\
6 & allyl alcohol & $54(3 \mathbf{a f})$ \\
\hline
\end{tabular}

[a] Reactions were run with $0.3 \mathrm{mmol}$ of $\mathbf{1 a}, 50 \mathrm{mg}$ of water, and $[\mathrm{RhCl}(\mathrm{cod})]_{2}(5 \% \mathrm{Rh})$ at $100^{\circ} \mathrm{C}$ under $10 \mathrm{~atm}$ of $\mathrm{CO}$ pressure in $5 \mathrm{~mL}$ of alcohol for $16 \mathrm{~h}$.

Next, we surveyed the scope of the method for various alcohols and enyne reagents under the established reaction conditions, that is at $100^{\circ} \mathrm{C}, 10 \mathrm{~atm}$ of $\mathrm{CO}$, in $5 \mathrm{~mL}$ of alcohol containing $50 \mathrm{mg}$ of water additive, and using $[\mathrm{RhCl}(\operatorname{cod})]_{2}(5 \% \mathrm{Rh})$ as the catalyst precursor. The carbonylative reaction of 1a with $\mathrm{MeOH}, \mathrm{EtOH}$, or primary saturated $\mathrm{C}_{3}$ and $\mathrm{C}_{4}$ alcohols all gave rise to the corresponding cyclic products in good isolated yields (Table 3, entries 1-4). Moderate yields of $\mathbf{3 a}$ products could also be obtained with a bulky alcohol, isopropyl alcohol, or a functionalized alcohol, allyl alcohol (entries 5 and 6).

Table 4 includes representative results of the rhodium-catalysed alkoxycarbonylation of various 1,6enynes with methanol. As shown, the method is suitable for enynes having a malonate-based tether bearing an ethyl or $\mathrm{CH}_{2} \mathrm{OMe}$ substituent on the alkynyl group as well as ester and ketone substituents on the outer olefinic carbon (entries 1-4) providing the corresponding methyl 2-(cyclopentenylidene)acetate derivatives in good isolated yields (3ba-3ea). Enyne 1f, having a trimethylene tether, gave a complex mixture and consequently, the desired product 3 fa was obtained in low yield as determined by ${ }^{1} \mathrm{H}$ NMR analysis (entry 5).

An oxygen-bridged enyne 1g was also an appropriate substrate, and accordingly converted to a methyl 2-[dihydrofuran-3(2H)-ylidene]acetate product 3ga in good yield (entry 6). Interestingly, the presence of a nitrogen functionality within the structure of enyne as a linker (1h) or a substituent on the olefinic site (1i and $\mathbf{1 i}^{\prime}$ ), gave rise to hydroesterification products $\mathbf{4}$ in addition to the formation of the desired products (entries 7-9).

It should be noted that the substrate $\mathbf{1 i}$ was a mixture of $E$ - and $Z$-isomers. When the substrate containing $E$ - and $Z$-1i isomers in a molar ratio of 3:1 was subjected to a carbonylation reaction in methanol, the yields of products 3ia and 4ia were obtained in the molar ratio $2: 1$. We also synthesised a cyanoallyl-substituted, dimethyl malonate-tethered enyne $\mathbf{1 i}^{\prime}$ in a higher $E$ to $Z$ isomeric ratio of 7.3:1 (see the Supporting Information) and conducted a carbonylation reaction using this isomeric mixture. It was interesting to find out that the latter substrate afforded 3ia' and $\mathbf{4} \mathbf{i a}^{\prime}$ in a higher yield ratio $(6: 1)$. That the $3: 4$ ratio of products is directly related with the $E: Z$ ratio of cyanoallyl-substituted enyne substrate charged into the reaction system indicates that the $\mathbf{4 i a}$ and $\mathbf{4} \mathbf{i a}^{\prime}$ by-

Table 4. Rhodium-catalysed methoxycarbonylative reaction of 1,6-enynes.

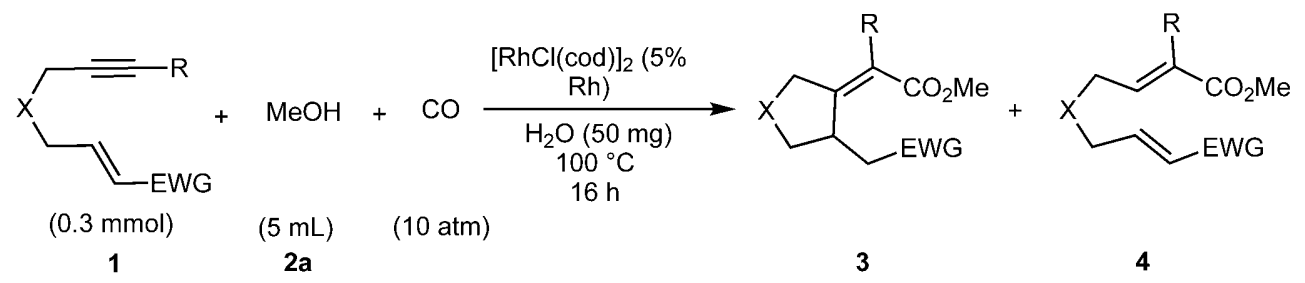

\begin{tabular}{lllll}
\hline Entry & $\mathrm{X}$ & $\mathrm{R}$ & $\mathrm{EWG}$ & Isolated Yield [\%] 3:4 \\
\hline 1 & $\mathrm{C}\left(\mathrm{CO}_{2} \mathrm{Et}\right)_{2}$ & $\mathrm{Et}$ & $\mathrm{CO}_{2} \mathrm{Me}$ & $61: 0(\mathbf{3 b a})$ \\
2 & $\mathrm{C}\left(\mathrm{CO}_{2} \mathrm{Et}\right)_{2}$ & $\mathrm{CH}_{2} \mathrm{OMe}$ & $\mathrm{CO}{ }_{2} \mathrm{Me}$ & $62: 0(\mathbf{3 c a})$ \\
$3^{[\mathrm{a}]}$ & $\mathrm{C}\left(\mathrm{CO}_{2} \mathrm{Me}\right)_{2}$ & $\mathrm{Me}$ & $\mathrm{COPh}$ & $71: 0(\mathbf{3 d a a})$ \\
4 & $\mathrm{C}\left(\mathrm{CO}_{2} \mathrm{Me}\right)_{2}$ & $\mathrm{CO}$ & $\mathrm{CO}_{2} \mathrm{Et}$ & $31: 0(\mathbf{3 f a})$ \\
5 & $\mathrm{CH}_{2}$ & $\mathrm{Me}$ & $\mathrm{CO}_{2} \mathrm{Et}$ & $68: 0(3 \mathbf{3 a})$ \\
6 & $\mathrm{O}$ & $\mathrm{Me}$ & $\mathrm{CO}_{2} \mathrm{Me}$ & $41: 14(\mathbf{3 h a})$ \\
7 & $\mathrm{NTs}$ & $\mathrm{Me}$ & $\mathrm{CN}$ & $44: 22(3 \mathbf{3 i a})$ \\
$8^{[\mathrm{b}]}$ & $\mathrm{C}\left(\mathrm{CO}_{2} \mathrm{Et}\right)_{2}$ & $\mathrm{Ce}$ & $54: 9(\mathbf{3 i a})$ \\
$9^{[\mathrm{c}]}$ & $\mathrm{C}\left(\mathrm{CO}_{2} \mathrm{Me}\right)_{2}$ & $\mathrm{Me}$ & $\mathrm{H}$ & $\mathrm{ND}^{[\mathrm{d}]}(\mathbf{3 j a})$ \\
10 & $\mathrm{C}\left(\mathrm{CO}_{2} \mathrm{Et}\right)_{2}$ & $\mathrm{Me}$ & & \\
\hline
\end{tabular}

\footnotetext{
[a] Performed with $8 \%$ of $\mathrm{Rh}$.

[b] The substrate $\mathbf{1 i}$ was an isomeric mixture of $E$ and $Z$ in the ratio of $3: 1$.

[c] The substrate 1i' was an isomeric mixture of $E$ and $Z$ in the ratio of 7.3/1.

[d] Not determined.
} 

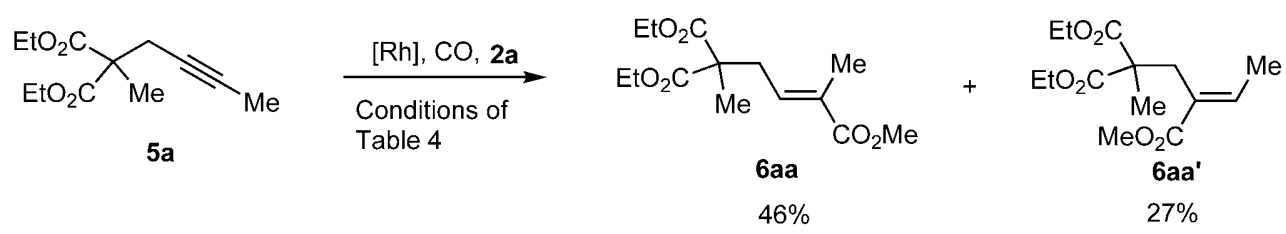

Scheme 3. Rhodium-catalysed methoxycarbonylation of diethyl 2-(but-2-ynyl)-2-methylmalonate (5a).

products were mainly formed from the $Z$-configured enynes $\mathbf{1 i}$ and $\mathbf{1} \mathbf{i}^{\prime}$, respectively

The methodology is not suitable for the enyne with an unsubstituted olefinic site (3ja). The carbonylation reaction of $\mathbf{1 j a}$ led to a complex mixture of isomers of cyclised and non-cyclised methoxycarbonylates with complete conversion (entry 10).

It has been considered that a dual interaction between substrate and rhodium species facilitates the 1,2-carborhodation step of alkynes and regulates the regioselectivity of the process. ${ }^{[9,12]}$ To evaluate whether such a promotive effect can also be legitimate for the alkoxycarbonylation of alkynes, we conducted an analogous reaction with the substrate $\mathbf{5 a}$, which lacks an alkenyl moiety. A regioisomeric hydroesterified mixture was formed from 5a indicating that coordination of the alkenyl moiety to rhodium has no significant influence on the reactivity of $\mathbf{1}$ towards alkoxycarbonylation, but rather governed the resulting regioselectivity with enynes (Scheme 3 ).

The method was also applied on several simple alkynes (Table 5). (E)-Methyl 2,3-diphenylacrylate (6ba) product was recovered in $65 \%$ yield from the reaction of diphenylacetylene in $\mathrm{MeOH}$ under the established conditions for enynes 1 (entry 1 ). Modification of experimental conditions which involved a lower reaction temperature of $80^{\circ} \mathrm{C}$ and catalyst loading $(3 \% \mathrm{Rh})$ with respect to the substrate improved the yield to $75 \%$ (entry 2). The method was also suitable for a dialkylacetylene, 4-octyne, yet not regioselective for hydroesterification of an unsymmetric alkyne, 1-phenylpropyne (entries 3 and 4).

The formation of double carbonylative products was negligible in our case. A double carbonylation product 5-alkoxy-2(5H)-furanone which was the major product type of a previous study ${ }^{[3]}$ was determined to be usually less than $3 \%$ within the complex by-product mixtures. Probably application of milder conditions, e.g., lower $\mathrm{CO}$ pressure and temperature, and absence of any base and ligand additives disfavoured the double carbonylation path.

In view of the results with enynes and alkynes, the rhodium-catalysed alkoxycarbonylative cyclisation of 1,6-enynes should proceed through a carboalkoxyrhodium intermediate $\mathbf{A},{ }^{[3]}$ followed by intramolecular cis addition to the triple bond in a regioselective manner to give the alkenylrhodium(I) B (Scheme 4). Intracarborhodation onto the tethered double bond (C)
Table 5. Rhodium-catalysed hydroesterification of alkynes.

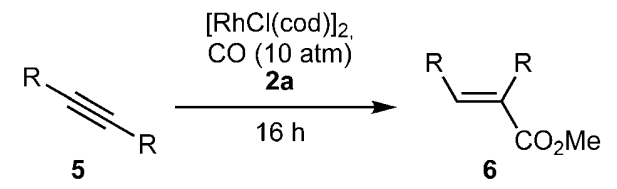

\begin{tabular}{lll}
\hline Entry & $\mathrm{R}$ & Isolated Yield [\%] \\
\hline $1^{[\mathrm{a}]}$ & $\mathrm{Ph}$ & $65(\mathbf{6 b a})$ \\
$2^{[\mathrm{b}]}$ & $\mathrm{Ph}$ & $75(\mathbf{6 b a})$ \\
$3^{[\mathrm{b}]}$ & $\mathrm{Pr}$ & $73(\mathbf{6 c a})$ \\
$4^{[\mathrm{b}]}$ & $\mathrm{Ph}, \mathrm{Me}$ & $80(1: 1)^{[\mathrm{c}]}(\mathbf{6 d a})$
\end{tabular}

[a] Performed under the conditions of Table 4.

[b] Performed with $1 \mathrm{mmol}$ of $\mathbf{5}$ and $3 \%$ of $\mathrm{Rh}$ in $10 \mathrm{~mL}$ of 2a at $80^{\circ} \mathrm{C}$.

[c] Isomeric ratio.

and subsequent protodemetalation steps generate the desired cyclised product $\mathbf{3}$.

Relatively stronger intramolecular coordination of the rhodium with the nitrogen functionality within the intermediate $\mathbf{B}$ could account for the formation of hydroesterification products when reacted with either the enyne $\mathbf{1 h}^{[13]}$ or $\mathbf{1 i}$ (Scheme 5). The existence of such coordinative interactions may obviate the next carborhodation step (formation of the intermediate C), leading to the protodemetalation hydroesterification products 4 ha and 4ia, respectively. It should be noted that such a coordinative interaction should be more achievable with the $Z$-configured isomer of $\mathbf{1 i}$ as compared to $E$-1i since its spatial arrangement would allow the rhodium and the nitrile group to adopt a closer distance.

In summary, we have presented within this report that rhodium-catalysed carbonylation of 1,6-enynes with an alkenyl moiety substituted by an electron withdrawing group in an alcohol constructs five-membered rings with an exocyclic alkenyl ester group. The method can also be applied on simple internal alkynes to construct $\alpha, \beta$-unsaturated esters.

\section{Experimental Section}

\section{Carbonylation Reactions}

A mixture of substrate, rhodium complex, and predried and degassed alcohol was added to a 50-mL stainless steel auto- 


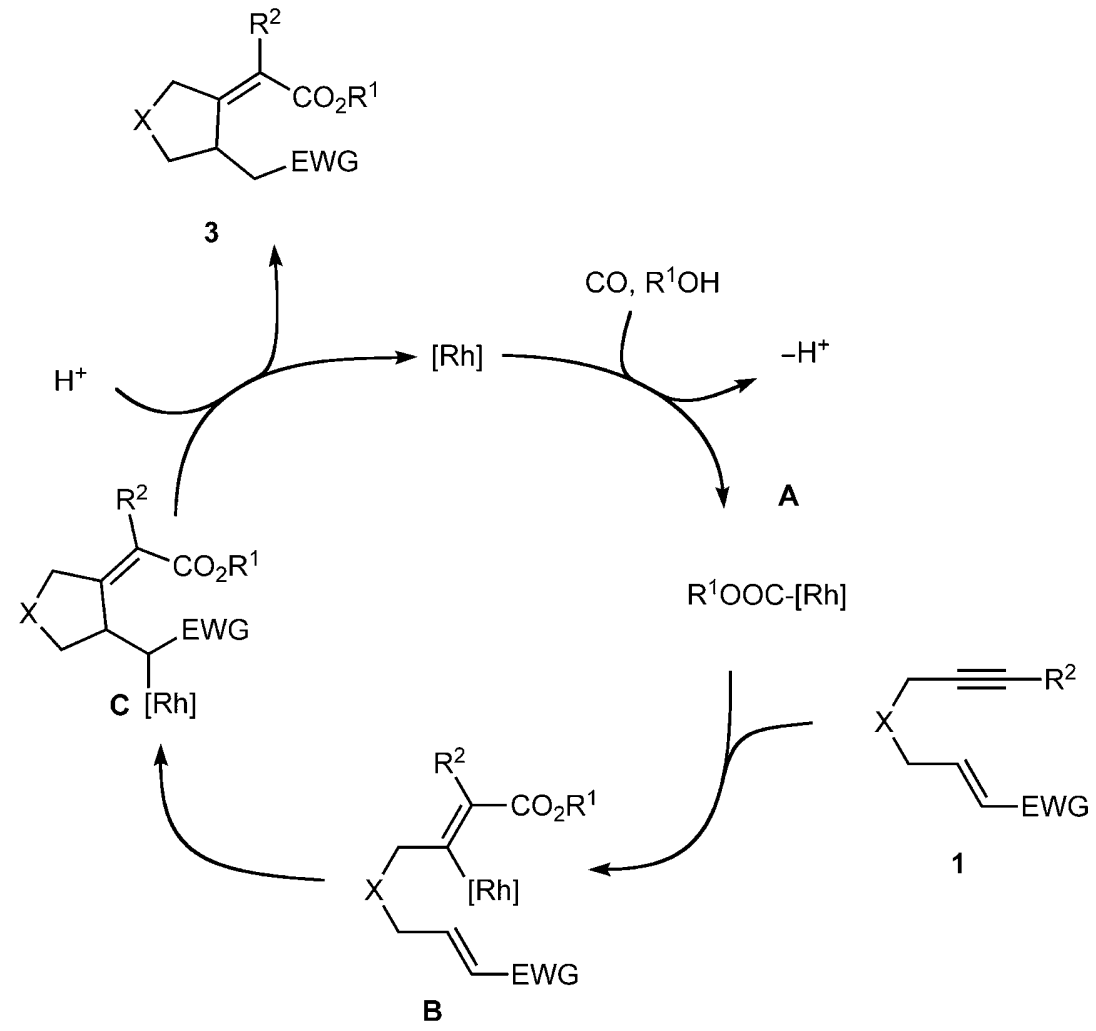

Scheme 4. Reaction mechanism for the alkoxycarbonylation of 1,6-enynes.<smiles>[3H]N(C/C=C/C(C)=O)C/C(C(C)=O)=C(\C)C(=O)OC</smiles><smiles></smiles>

Scheme 5. Alkenylrhodium(I) intermediates (C) which may arise from the enynes $\mathbf{1 h}$ and $\mathbf{Z}-\mathbf{1 i}$.

clave containing a glass insert tube. Then, the sealed autoclave was evacuated and purged with $10 \mathrm{~atm} \mathrm{CO}$ twice, successively. Subsequently, the reactor was pressurised with $\mathrm{CO}$ and the mixture was stirred magnetically in a preheated oil bath. After cooling, the reaction mixture was recovered with ethyl acetate. The solvent was evaporated and the residue was purified by flash chromatography (hexane-EtOAc), affording the product.

\section{Acknowledgements}

The support of The Scientific and Technological Research Council of Turkey (TBAG-108T985), and IZTECH (2009IYTE-19) to this work is gratefully acknowledged. We thank Ms. I. Özçelik, Mr. S. Günnaz, and Dr. W. Hiller for NMR analyses and Dr. H. Özgener for FT-IR analyses, and Dr. R. Eanes for proof reading.

\section{References}

[1] a) G. Kiss, Chem. Rev. 2001, 101, 3435-3456; b) A. Brennführer, H. Neumann, M. Beller, ChemCatChem 2010, 2, 509-513; c) J. F. Knifton, J. Mol. Catal. 1977, 2, 293-299; d) B. E. Ali, H. Alper, J. Mol. Catal. 1991, 67, 29-33; e) K. Itoh, M. Miura, M. Nomura, Tetrahedron Lett. 1992, 33, 5369-5372; f) E. I. Drent, P. Arnoldy, P. H. M. Budzelaar, J. Organomet. Chem. 1993, 455, 247-253; g) M. T. Reetz, R. Demuth, R. Goddard, Tetrahedron Lett. 1998, 39, 7089-7092; h) B. E. Ali, J. Tijani, A. M. El-Ghanam, Tetrahedron Lett. 2001, 42, 2385-2387; i) M. Akao, S. Sugawara, K. Amino, Y. Inoue, J. Mol. Catal. A: Chem. 2000, 157, 117-122; Ptcatalysed: j) Y. Tsuji, T. Kondo, Y. Watanabe, J. Mol. Catal. 1987, 40, 295-304.

[2] A. Vizer, K. B. Yerzhanov, A. A. A. A. Quntar, V. M. Dembitsky, Tetrahedron 2004, 60, 5499-5538.

[3] T. Mise, P. Hong, H. Yamazaki, J. Org. Chem. 1983, 48, 238-242.

[4] E. Yoneda, T. Kaneko, S.-W. Zhang, K. Onitsuka, S. Takahashi, Tetrahedron Lett. 1999, 40, 7811-7814.

[5] S. Inoue, K. Yokota, H. Tatamidani, Y. Fukumoto, N. Chatani, Org. Lett. 2006, 8, 2519-2522.

[6] a) K. Doyama, T. Joh, K. Onitsuka, T. Shiohara, S. Takahashi, J. Chem. Soc. Chem. Commun. 1987, 649-650; b) T. Joh, K. Doyama, K. Onitsuka, T. Shiohara, S. Takahashi Organometallics 1991, 10, 2493-2498. A COfree hydrocyclocarbonylation process: c) K. Fuji, T. Morimoto, K. Tsutsumi, K. Kakiuchi, Chem. Commun. 2005, 3295-3297. 
[7] S. Inoue, Y. Fukumoto, N. Chatani, J. Org. Chem. 2007, $72,6588-6590$.

[8] a) Ö. Aksın, N. Dege, L. Artok, H. Türkmen, B. Çetinkaya, Chem. Commun. 2006, 3187-3189; b) M. Kuş, Ö. Aksin-Artok, F. Ziyanak, L. Artok, Synlett 2008, $2587-$ 2592; c) L. Artok, M. Kuş, Ö. Aksın-Artok, F. N. Dege, F. Y. Özkılınç, Tetrahedron 2009, 65, 9125-9133.

[9] a) T. Miura, M. Murakami, Chem. Commun. 2007, 217-224, and references cited therein; b) S. W. Youn, Eur. J. Org. Chem. 2009, 2597-2605, and references cited therein; c) T. Miura, M. Yamauchi, M. Murakami, Synlett 2007, 2029-2032; d) L. Artok, M. Kuş, B. N. Ürer, G. Türkmen, Ö. Aksın-Artok, Org. Biomol. Chem. 2010, 8, 2060-2067; e) M. Lautens, T. Marquardt, J. Org. Chem. 2004, 69, 4607-4614.

[10] a) C. Liu, R. A. Widenhoefer, Organometallics 2002, 21, 5666-5673; b) S. E. Denmark, J. H.-C. Liu, J. Am. Chem. Soc. 2007, 129, 3737-3744.
[11] T. Shibata, Adv. Synth. Catal. 2006, 348, 2328-2336.

[12] a) R. Shintani, A. Tsurusaki, K. Okamoto, T. Hayashi, Angew. Chem. 2005, 117, 3977-3980; Angew. Chem. Int. Ed. 2005, 44, 3909-3912; b) T. Miura, M. Shimada, M. Murakami, J. Am. Chem. Soc. 2005, 127, 10941095; c) T. Miura, M. Shimada, M. Murakami, Chem. Asian J. 2006, 1, 868-877.

[13] Sulfonamides can complex with rhodium: a) I. Karamé, M. Jahjah, A. Messaoudi, M. L. Tommasino, M. Lemaire, Tetrahedron: Asymmetry 2004, 15, 1569-1581; b) N. A. Cortez, R. Rodríguez-Apodaca, G. Aguirre, M. Parra-Hake, T. Coleb, R. Somanathan, Tetrahedron Lett. 2006, 47, 8515-8518; c) N. A. Cortez, G. Aguirre, M. Parra-Hake, R. Somanathan, Tetrahedron: Asymmetry 2008, 19, 1304-1309. 